\title{
Grounds for Searching the Best Solution for Controlling the Pressurized Water Reactor in Dynamic Modes when Changing the Controlled Parameters
}

\author{
Taia Petik ${ }^{*}$, Viktoriia Vataman, Konstantin Beglov, Anna Lysyuk \\ Odessa National Polytechnic University, 1 Shevchenko Avenue, Odessa, 65044, Ukraine \\ Received: March 23, 2021. Revised: April 12, 2021. Accepted: April 19, 2021.
}

(c) 2021 The authors. Published by Lviv Polytechnic National University.

\begin{abstract}
The article focused on the development of information technology for the optimization of control over complex dynamic systems at the stage of their design that should realize possibilities of modeling of linear and nonlinear dynamic systems, the analysis and synthesis of such systems, their optimization on various quality criteria. The purpose of this article is to develop the structure and elements of information technology to optimize the control of complex dynamic systems, including automated control systems. The general structure and functional model of information technology of the analysis and synthesis of control systems includes modeling of dynamic systems in the form of systems of differential equations and transfer functions, integration of systems of differential equations, calculation of system quality criteria, methods for solving various optimization tasks on solutions of optimization problems of dynamic systems is offered.
\end{abstract}

Keywords: information technology; dynamic system; quality index; steam generator; automatic control system; pressurized water reactor.

\section{Introduction}

The structure of information-analytical technology (IAT) includes a block of systems models (BSM), a module of integration methods (MIM), a block for calculating system quality criteria, a block of optimization methods (BOM), a module of data structures and a block for presenting information. A functional model of information technology is presented.

The block of system models is designed to set the parameters of models of information and control systems (ICS) [1]-[3], the corresponding systems of differential equations (SDE) and transfer functions (TF). This unit includes models of nuclear reactors, steam generators, steam turbines, their automated control systems (ACS), ACS of water treatment, power unit and its ACS, and other models. Automated control systems include regulators of various types [1]-[4].

The module of integration methods is connected with the block of models of systems and is intended for the decision of SDE by various methods of integration. Matrix integration methods are selected in this module: matrix exponent method, system methods of the first, second and third degrees.

The module of criteria of systems is intended for calculation of various criteria of ACS on the basis of their models in the form of SDE or TF. This module includes: criteria for the stability of ACS, identification criteria, methods for calculating direct quality indicators (DQI) based on the integration of SDE, methods for calculating integrated quadratic estimates (IQE) based on TF.

\footnotetext{
${ }^{*}$ Corresponding author. Email address: taiapetik@gmail.com
}

This paper should be cited as: T. Petik, V. Vataman, K. Beglov, A. Lysyuk. Grounds for searching the best solution for controlling the pressurized water reactor in dynamic modes when changing the controlled parameters. Energy Engineering and Control Systems, 2021 Vol. 7, No. 1, pp. 56 - 61. https://doi.org/10.23939/jeecs2021.01.056 
The block of optimization methods is designed to solve the problems of model parameter identification and synthesis of optimal ICS. This block contains methods of one-dimensional search, methods of multidimensional unconditional optimization, methods of conditional optimization, methods of minimizing the sum of squares, methods of global search, genetic algorithms, vector optimization methods. BOM uses the functions of the module of system criteria (MSC).

A module of data structures has been developed for the interaction of all elements of IAT. This module includes the structure of constant parameters of optimization problems, the structure of data of optimization processes, the structure of functions for optimization problems and methods of processing these structures.

The information presentation module is designed for tabular and graphical output of information for solving problems of analysis, identification and synthesis of ICS. This module uses data structures from the previous module.

\section{The structure of information technology}

The general structure of information-analytical technology of analysis and synthesis of control systems includes 6 main functional elements (Fig. 1): block of system models, module of integration methods, module of system criteria, block of optimization methods, module of data structures and module for presenting information is developed. In this article we will consider only four main blocks.

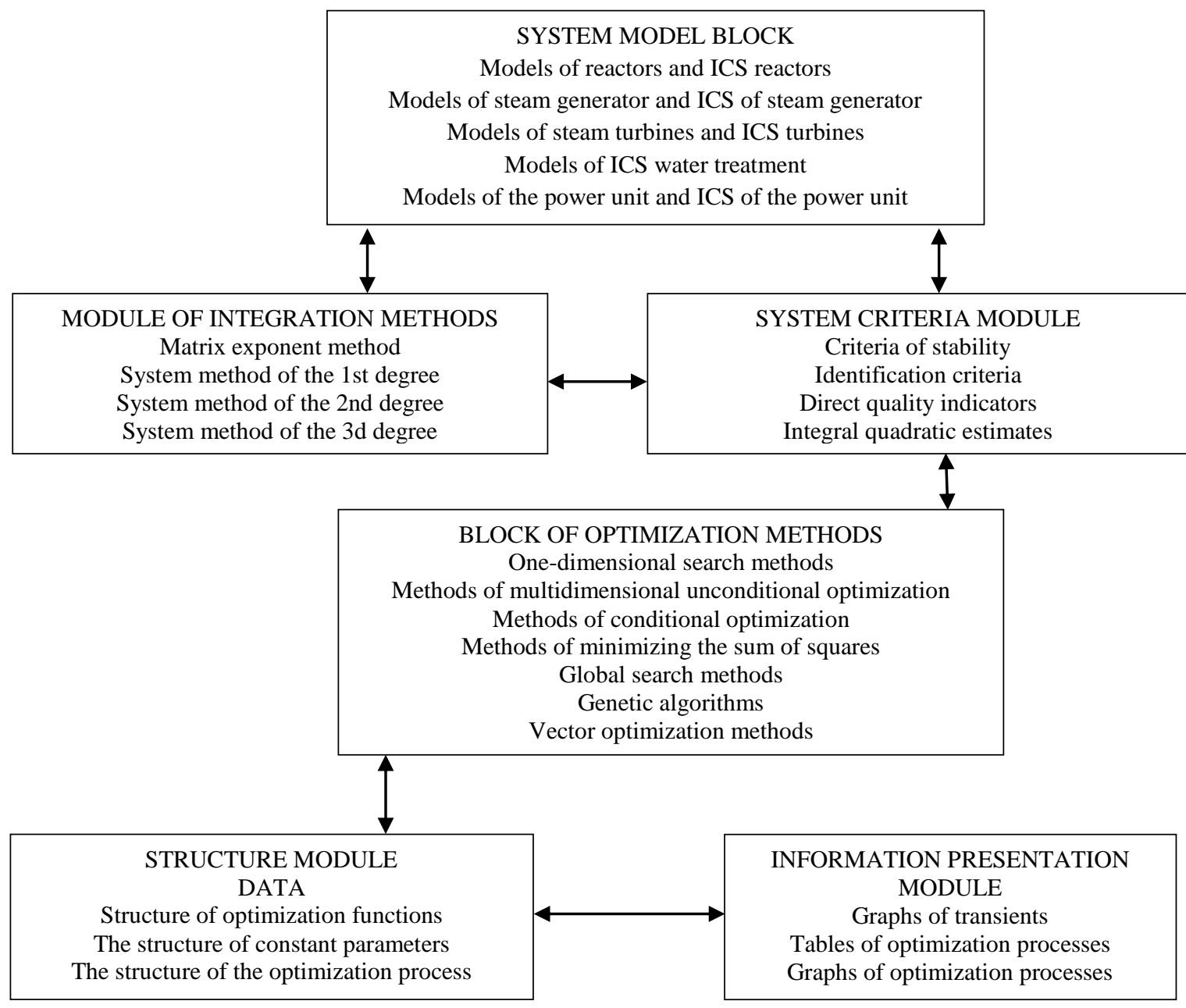

Fig. 1. The structure of information and analytical technology

In general, the structure of IAT, which is presented in Fig. 1, allows you to solve a wide range of ICS research problems. 


\subsection{Block of system models}

For analysis and synthesis of dynamic systems, in particular control systems of power units of nuclear power plants (NPP), their mathematical models are built. The general mathematical model of a dynamical system is represented as:

$$
\frac{d X}{d t}=\boldsymbol{f}(\boldsymbol{X}, \boldsymbol{x}, \boldsymbol{c}, \boldsymbol{g}), \quad \boldsymbol{X}_{\mathbf{0}}=\boldsymbol{X}\left(t_{0}\right), \quad y=\boldsymbol{C}_{y}(\boldsymbol{X})
$$

where $t$ and $t_{0}$ are time variable and its initial value; $\mathbf{X}=\mathbf{X}(\mathrm{t})$ and $\mathbf{X}_{0}$ are state and initial condition vectors; $\mathbf{f}(\mathbf{X}, \mathbf{X}, \mathbf{c}, \mathbf{g})$ is vector function of the right parts of the SDE; $\mathbf{x}$ and $\mathbf{c}$ are vectors of variable and constant parameters of ICS; $\mathbf{g}$ is vector of external actions; $\mathbf{C}_{\mathrm{y}}(\mathbf{X})$ is model output operator; $\mathbf{y}$ is vector of source variables. In the form (1) models of elements of control systems of NPP power units and the general control system of the power unit, and also models of control system of the quadcopter [5], generators of impulses of tension and current, Butterworth [6] filters are compared.

Real control systems of NPP power units [7] are implemented according to the generalized structural scheme presented in Fig. 2, where the following notations are accepted: $R$ is regulator, $C O$ is control object, $g$ is set point, $\varepsilon$ is control error, $u$ is control action, $v$ is external disturbance, $y$ is controlled parameter.

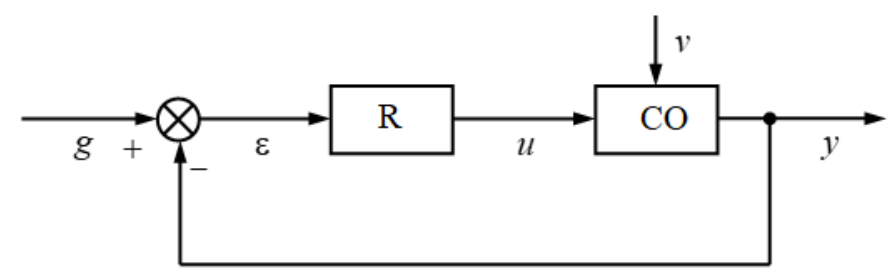

Fig. 2. General structural scheme of the control system

The set point $g$ and the controlled parameter $y$ are fed to the adder. Negative feedback generates an error signal $\varepsilon=g-y$. The error signal is fed to the controller $R$, which forms a control action $u$. This action is applied to the control object, which is also affected by external disturbances $v$. These influences change the state of the control object and ultimately the controlled parameter $y$.

All actions and signals in Fig. 2 are functions of time $t: g=g(t), \varepsilon=\varepsilon(t), u=u(t), v=v(t), y=y(t)$.

The general mathematical model of $\mathrm{CO}$ is:

$$
\frac{d X_{O}}{d t}=f_{O}\left(X_{O}, x_{O}, c_{O}, g_{O}\right), \quad X_{0 O}=X_{O}\left(t_{0}\right), \quad y=C_{y}\left(X_{O}\right)
$$

where $\mathbf{X}_{\mathrm{O}}=\mathbf{X}_{\mathrm{O}}(\mathrm{t})$ and $\mathbf{X}_{0 \mathrm{O}}$ are vectors of state and initial conditions of the control object; $\mathbf{f}_{\mathrm{o}}\left(\mathbf{X}_{\mathrm{o}}, \mathbf{x}_{\mathrm{o}}, \mathbf{c}_{\mathbf{o}}, \mathbf{g}\right)$ is vector function of the right parts of the SDE of the object; $\mathbf{x}_{\mathrm{O}}$ and $\mathbf{c}_{\mathrm{O}}$ are vectors of variable and constant parameters of the $\mathrm{CO} ; \mathbf{g}_{\mathrm{O}}=(\mathrm{u}, \mathrm{v})^{\mathrm{T}}$ is vector of external actions; $\mathrm{C}_{\mathrm{y}}\left(\mathbf{X}_{\mathrm{O}}\right)$ is object exit operator. In the form (2) models of $\mathrm{CO}$ are compared: nuclear reactor, steam generator, steam turbine, water treatment elements and the whole power unit, as well as a quadcopter [5].

The general mathematical model of the regulator is:

$$
\frac{d \boldsymbol{X}_{C}}{d t}=\boldsymbol{f}_{C}\left(\boldsymbol{X}_{C}, \boldsymbol{x}_{C}, \boldsymbol{c}_{C}, \varepsilon\right), \quad \boldsymbol{X}_{0 C}=\boldsymbol{X}_{C}\left(t_{0}\right), \quad u=C_{u}\left(\boldsymbol{X}_{C}\right),
$$

where $\mathbf{X}_{\mathrm{C}}=\mathbf{X}_{\mathrm{C}}(\mathrm{t})$ and $\mathbf{X}_{0 \mathrm{C}}$ are vectors of state and initial conditions of the regulator; $\mathbf{f}_{\mathrm{c}}\left(\mathbf{X}_{\mathrm{c}}, \mathbf{x}_{\mathrm{c}}, \mathbf{c}_{\mathrm{c}}, \varepsilon\right)$ is vector function of the right parts of the SDE regulator; $\mathbf{x}_{\mathrm{C}}$ and $\mathbf{c}_{\mathrm{C}}$ are vectors of variable and constant parameters of the regulator; $\mathrm{C}_{\mathrm{u}}\left(\mathbf{X}_{\mathrm{C}}\right)$ is regulator output operator. Information technology makes it possible to use different types of regulators, which include proportional (P), integral (I) and differential (D) regulators, which form the control actions:

$$
u_{P}=K_{P} \varepsilon, \quad u_{I}=\frac{1}{T_{I}} \int \varepsilon d t, \quad u_{D}=\tau_{D} \frac{d \varepsilon}{d t} .
$$

Here $K_{p}, T_{I}$ and $\tau_{D}$ are parameters of regulators. The following TF correspond to those P, I and D control laws of regulators: 


$$
W_{P}=K_{P}, \quad W_{I}(s)=\frac{1}{T_{I} s}, \quad W_{D}(s)=\frac{K_{D} T_{D} s}{T_{D} s+1} .
$$

The last TF at $K_{D}>1$ approximately forms a differential law with parameter $\tau_{\mathrm{D}}=K_{D} T_{D}$. Usually $K_{D}=10$. Denoting $\lambda_{\mathrm{I}}=1 / T_{I}, \lambda_{\mathrm{D}}=1 / T_{D}$, we write the differential equations (DE) of I regulator and $\mathrm{D}$ regulator:

$$
\frac{d u_{I}}{d t}=\lambda_{I} \varepsilon, \quad \frac{d v_{D}}{d t}=-\lambda_{D}\left(v_{D}+K_{D} \varepsilon\right), \quad u_{D}=v_{D}+K_{D} \varepsilon
$$

From P, I and D regulators we will build PI, PD, ID and PID regulators. To optimize the parameters of the regulators $K_{P}, \lambda_{\mathrm{I}}$ and $\lambda_{\mathrm{D}}$, we form from them a vector of variable parameters $\mathrm{x} \in \mathrm{R}^{\mathrm{p}}$ of size $\mathrm{p} \in\{1,2,3\}$. For $\mathrm{P}$ and $\mathrm{I}$ regulators $p=1$, for $\mathrm{PI}, \mathrm{PD}$ and ID regulators $p=2$, for PID regulator $p=3$.

The general model of ACS has the form (1), where by equations (2) and (3) $\mathbf{X}=\left(\mathbf{X}_{\mathrm{O}}(\mathrm{t}), \mathbf{X}_{\mathrm{C}}(\mathrm{t})\right)^{\mathrm{T}}, \mathbf{f}(\mathbf{X}, \mathbf{x}, \mathbf{c}, \mathbf{g})=$ $\left(\mathbf{f}_{\mathrm{O}}\left(\mathbf{X}_{\mathrm{O}}, \mathbf{x}_{\mathrm{O}}, \mathbf{c}_{\mathrm{O}}, \mathbf{g}_{\mathrm{O}}\right), \mathbf{f}_{\mathrm{C}}\left(\mathbf{X}_{\mathrm{C}}, \mathbf{x}_{\mathrm{C}}, \mathbf{c}_{\mathrm{C}}, \mathrm{g}-\mathrm{y}\right)\right)^{\mathrm{T}}$. Models of ICS of a nuclear reactor, steam generator, steam turbine, water treatment elements and the whole power unit, as well as a quadcopter are compared with these designations in the form of (1).

In some cases, to increase the speed of calculations from the general nonlinear model (1), we turn to the linear model

$$
\frac{d X}{d t}=\boldsymbol{A}(\boldsymbol{x}) \boldsymbol{X}+\boldsymbol{B}(\boldsymbol{x}) \boldsymbol{g}, \quad X_{0}=\boldsymbol{X}\left(t_{0}\right), \quad y=\boldsymbol{C}(\boldsymbol{x}) \boldsymbol{X},
$$

where $\mathbf{A}(\mathbf{x}), \mathbf{B}(\mathbf{x}), \mathbf{C}(\mathbf{x})$ are state, input and output matrices.

The transfer function corresponds to this model:

$$
W(\boldsymbol{x}, s)=\frac{\beta(\boldsymbol{x}, s)}{\alpha(\boldsymbol{x}, s)}, \quad \alpha(\boldsymbol{x}, s)=\sum_{i=0}^{n} \alpha_{i}(\boldsymbol{x}) s^{n-i}, \quad \beta(\boldsymbol{x}, s)=\sum_{i=0}^{m} \beta_{i}(\boldsymbol{x}) s^{m-i}
$$

Mathematical models of specific dynamic systems in the form of SDE or TF, in particular control systems of NPP power units, are implemented in the modules of these systems [8].

\subsection{Module of integration methods}

Numerical methods of integration are used to construct transients in dynamical systems, as well as the calculation of direct indexes of the quality of systems. Matrix integration methods are chosen to increase accuracy and reliability.

Consider the integration of SDE (1) and (4) in the interval [0, $\left.T_{f}\right]$ for $L$ steps of solving SDE (4) of constant length $h=T_{f} / L$. Since the vector of variable parameters of ICS $\mathrm{x}$ does not change in the process of SDR integration, we denote $\mathbf{A}=\mathbf{A}(\mathbf{x}), \mathbf{B}=\mathbf{B}(\mathbf{x}), \mathbf{C}=\mathbf{C}(\mathbf{x}), \mathrm{t}_{\mathrm{k}}=\mathrm{kh}, \mathbf{X}_{\mathrm{k}}=\mathbf{X}\left(\mathrm{t}_{\mathrm{k}}\right), \mathrm{y}_{\mathrm{k}}=\mathrm{y}\left(\mathrm{t}_{\mathrm{k}}\right), k=\overline{0, L}$

$$
\boldsymbol{e}(\boldsymbol{A}, h)=e^{A h}, \quad \boldsymbol{I}(\boldsymbol{A}, h)=\int_{0}^{h} e^{\boldsymbol{A} t} d t, \quad \boldsymbol{G}=\boldsymbol{I}(\boldsymbol{A}, h) \boldsymbol{B},
$$

where $e(A, h)$ is matrix exponent; $I(A, h)$ is the integral of the matrix exponent; $G$ is auxiliary matrix. The matrix exponent and its integral are calculated as matrix series while minimizing the number of calculations without reducing the accuracy.

The matrix exponent method is used to integrate the linear SDE (5) by the formulas:

$$
X_{0}=\mathbf{0}, y_{0}=0, X_{k}=\boldsymbol{e}(\boldsymbol{A}, h) X_{k-1}+\boldsymbol{G}, y_{k}=\boldsymbol{C} X_{k}, k=\overline{1, L}
$$

According to the presented algorithms the programs of methods of integration of SDE which are elements of the module of methods of integration are written.

\subsection{Module of system criteria}

The module of system criteria formalizes methods and creates programs for calculating various criteria of automated control systems: methods of calculation of direct indicators of quality of systems, criteria of stability of automated control systems, methods of calculation of integrated quadratic estimations, identification criteria. 
Algorithms for calculating various criteria are presented, according to which programs of methods of criteria and objective functions are written.

For linear systems, the stability criteria use a characteristic polynomial of order $n$

$$
\alpha(s)=\alpha_{0} s^{n}+\alpha_{n-1} s^{n-1}+\alpha_{n-2} s^{n-2}+\cdots+\alpha_{n-1} s+\alpha_{n}, \quad \alpha_{0}>0,
$$

where $s$ is complex variable. The use of VOF to solve the problems of identification and optimization of ICS allows you to automate and accelerate the process of solving these problems with the consistent implementation of all requirements for systems.

The module of system criteria formalizes methods and creates programs for calculating various criteria of automated control systems: methods of calculation of direct indicators of quality of systems, criteria of stability of automated control systems, methods of calculation of integrated quadratic estimations, identification criteria. Algorithms for calculating various criteria are presented, according to which programs of methods of criteria and objective functions are written.

\subsection{Block of optimization methods}

The block of optimization methods contains programs of optimization methods: methods of one-dimensional search, methods of multidimensional unconditional optimization, methods of conditional optimization, methods of minimizing the sum of squares, methods of global search, genetic algorithms, vector optimization methods [9].

To test the methods, test function modules have been created, which include the test functions themselves, their databases and testing programs. A utility module which contains general routines of optimization methods has been developed for the universality. If a feature is set to remember the optimization process, the optimization process is stored in an external file. This process can be displayed or continued.

The main features of the main modules of information technology optimization were considered and their interaction was analyzed to solve optimization problems. Extensive methodological, mathematical, tabular and graphical capabilities of information technology optimization of complex systems require the transfer of large amounts of data between subroutines. To reduce the number of formal parameters of subroutines, increase reliability and simplify the coordination of the program set during its development without changing the interface parts of subroutines, global data structures are proposed - OPTIONS, STATE and OPTFUNS. These global structures significantly increase the flexibility of the block of optimization methods and simplify its further development, as the interface of the subroutines, associated with the minimum possible number of input and output formal parameters, is virtually unchanged [10].

\section{Conclusion}

This article focuses on the development of elements of information technology to optimize the control of complex dynamic systems. The general structure of information-analytical technology of analysis and synthesis of control systems includes the following elements: block of system models, module of integration methods, module of system criteria, block of optimization methods, module of data structures and module for presenting information is developed. In the block of system models in the form of nonlinear and linear systems of differential equations and transfer functions, the general mathematical models of dynamic systems, in particular control objects, regulators, automated control systems are formalized that allows modeling control systems of NPP power units, quadcopter control system, voltage and current pulse generators, Butterworth filters and other dynamic systems. The module of integration methods formalizes numerical methods of integration of systems of differential equations, which are used to construct transients in dynamical systems, as well as to calculate direct indicators of system quality. To increase the accuracy and reliability, matrix integration methods are selected: matrix exponent method for integration of linear systems, system methods of the first, second and third stages for integration of nonlinear systems. Algorithms of integration methods and their auxiliary parameters are developed. A block of optimization methods, which contains modules of different types of optimization methods (one-dimensional search methods, multidimensional unconditional optimization methods, methods of conditional optimization, methods of minimizing the sum of squares, methods of global search, genetic algorithms, vector optimization methods), has been developed. To reduce the number of formal parameters of subroutines, increase reliability and coordinate the work of a set of programs during 
its development, a module of general data structures has been developed. Global data structures were proposed - the structure of constant data problems and optimization methods, the structure of variable parameters of the optimization process and the structure of functions to coordinate the interaction of optimization methods. These structures significantly increase the flexibility of the block of optimization methods and simplify its further development, as the interface of the subroutines, associated with the minimum possible number of input and output formal parameters, is virtually unchanged. A module for presenting problem-solving information in the form of three submodules has been developed, in which textual and graphical possibilities of information technology are implemented, that allow representing the optimization process in the form of tables and graphics.

\title{
References
}

[1] Bastrikov M.V., Ponomarev O.P. Information technologies control. Moscow, EKSMO Publ., 2002. 391 p. (in Russian)

[2] Pavlov A.A., Telenik S.F. Information technologies and algorithms in control. Kiev, Tekhnika Publ., 2002. 344 p. (in Ukrainian)

[3] Ershova N.M. Modern methods of the theory of design and control of complex dynamic systems: monograph. Dnepropetrovsk, PRASA Publ., 2016. 272 p. (in Ukrainian)

[4] Yastrebenetskiy M.A., Vasil'chenko V.N., Vinogradov S.V. Nuclear power plant safety: information and control Systems. Kiev, Tekhnika Publ., 2004. 472 p. (in Ukrainian)

[5] Nikulina E.N. Development of the controller for the quadcopter Finken in simulation enviroment Vrep / V.P. Severin, E.N. Nikulina, V.S. Buriakovskyi // Bulletin of the National Technical University "Kharkiv Polytechnic Institute" (series: Systems analysis, management and information technology). - Kharkiv: NTU «KhPI», 2016. - No. 37 (1209). - pp. 9-12. (in Ukrainian)

[6] Nikulina E.N. Analysis of electronic Butterworth filters by numerical methods / Severin V.P., Nikulina E.N., Buriakovskyi V.S., // Bulletin of the National Technical University "Kharkiv Polytechnic Institute" (series: Systems analysis, management and information technology). Kharkiv: NTU «KhPI», 2014. - No. 55 (1097). - pp. 19-24. (in Ukrainian)

[7] Maksymov M.V. Models of the Nuclear Power Unit WWER-1000 Using Data Mining Techniques / Tymur Foshch, Filipe Portela, José Machado, // Procedia Computer Science - 2016- Vol. 100 - Pp. 253-262.

[8] Nikulina E.N., Severin V.P., Lukidova D.A. Mathematical models for the study of transient modes of the WWER-1000 nuclear reactor of the V-320 series, 2018. No. 1(77). Pp. 18-23. (in Russian)

[9] Nikulina E.N. Block of optimization methods for information technology of control of complex dynamic systems / Severin V.P., Nikulina E.N., Shevtsov O.C. // Information technologies: science, engineering, technology, education, health: Abstracts of the XXVII International Scientific and Practical Conference MicroCAD-2019, Pt. I. - Kharkiv: NTU «KhPI», 2019. - P. 41. (in Ukrainian)

[10] Maksymov M.V. Regression Maksymov M.V. Method for controlling a reactor plant with WWER-1000 in maneuverable mode / Maksymov M.V., Tsiselskaya T.A., Kokol E.A. // Problems of Control and Informatics: Intern. scientific and technical journal. -2015. - No. 3. - pp. 59-75. (in Russian)

\section{Основи пошуку найкращого рішення для управління водо-водяним ядерним реактором в динамічних режимах при зміні регульованих параметрів}

\author{
Тая Петік, Вікторія Ватаман, Костянтин Беглов, Ганна Лисюк
}

Одеський національний політехнічний університет, проспект Шевченка 1, Одеса, 65044, Україна

\section{Анотація}

Стаття присвячена розробці інформаційної технології оптимізації управління складними динамічними системами на етапі їх проектування, котра повинна реалізовувати можливості моделювання лінійних і нелінійних динамічних систем, аналізу і синтезу цих систем, їх оптимізації за різними критеріями якості. Задача полягає у розробці структури та елементів інформаційної технології оптимізації управління складними динамічними системами, зокрема автоматизованих систем управління. Пропонується загальна структура i функціональна модель інформаційної технології аналізу та синтезу систем управління, яка включає моделювання динамічних систем у вигляді систем диференціальних рівнянь та передавальних функцій, інтегрування систем диференціальних рівнянь, обчислення критеріїв якості систем, методи для розв'язання різних задач оптимізації, наочне представлення інформації щодо розв'язків задач оптимізації динамічних систем.

Ключові слова: інформаційна технологія; складні динамічні системи; показник якості; парогенератор; автоматична система управління; водо-водяний ядерний реактор. 